\title{
Urological Emergency in a University Hospital Setting: Epidemiological, Diagnostic and Therapeutic Aspects
}

\author{
Modou Ndiaye ${ }^{1}$, Ousmane Sow ${ }^{1, *}$, Alioune Sarr ${ }^{1}$, Abdoulaye Ndiath ${ }^{1}$, Cyrille Ze Ondo ${ }^{1}$, \\ Babacar Sine ${ }^{1}$, Amath Thiam ${ }^{1}$, Ndeye Aissatou Bagayogo ${ }^{1}$, Samba Thiapato Faye ${ }^{1}$, \\ Ndiaga Seck Ndour', Aboubacar Traore ${ }^{3}$, Omar Gaye ${ }^{2}$, Ngor Mack Thiam ${ }^{2}$, El Hadj Malick Diaw ${ }^{1}$, \\ Yaya Sow ${ }^{1}$, Babacar Diao ${ }^{1}$, Alain Khassim Ndoye ${ }^{1}$ \\ ${ }^{1}$ Urology-Andrology Department, Aristide Le Dantec Hospital, Dakar, Senegal \\ ${ }^{2}$ Urology-Andrology Department, Idrissa Pouye Hospital, Dakar, Senegal \\ ${ }^{3}$ Urology-Andrology Department, De la Paix Hospital, Ziguinchor, Senegal
}

Email address:

sowman87@yahoo.fr (O. Sow)

${ }^{*}$ Corresponding author

To cite this article:

Modou Ndiaye, Ousmane Sow, Alioune Sarr, Abdoulaye Ndiath, Cyrille Ze Ondo, Babacar Sine, Amath Thiam, Ndeye Aissatou Bagayogo, Samba Thiapato Faye, Ndiaga Seck Ndour, Aboubacar Traore, Omar Gaye, Ngor Mack Thiam, El Hadj Malick Diaw, Yaya Sow, Babacar Diao, Alain Khassim Ndoye. Urological Emergency in a University Hospital Setting: Epidemiological, Diagnostic and Therapeutic Aspects. International Journal of Clinical Urology. Vol. 4, No. 2, 2020, pp. 51-54. doi: 10.11648/j.ijcu.20200402.13

Received: June 15, 2020; Accepted: July 2, 2020; Published: July 13, 2020

\begin{abstract}
Aim: To report the epidemiological and diagnostic aspects and evaluate the management of urological emergency in a university hospital. Patients and method: We conducted a single-center retrospective descriptive study over the period January 2015 to December 2017. We collected medical records of patients with urological emergency referred by the urology care team in our center. Results: Three hundred patients were identified over a period of 36 months. The mean age of the patients was $47.8 \pm 22.9$ years ( 2 years - 92 years). The sex-ratio was 10.5 . The most common emergency was haematuria $(25.6 \%)$ and urinary retention $(21.6 \%)$. Urogenital infections were noted in $19 \%$ of patients mostly scrotal cellulitis $(10 \%)$ and acute pyelonephritis (3.6\%). The number of emergency hospitalization was $230(76.7 \%)$. We performed 143 emergency surgical procedures $(47.6 \%)$. The overall mortality rate was $1 \%$. Conclusion: Urological emergency were dominated in our context by hematuria and urinary retention occurring most often in young adults. However, infectious and lithiasic diseases remain common conditions.
\end{abstract}

Keywords: Emergencies, Urinary Retention, Hematuria, Cellulitis

\section{Introduction}

Emergency evoke suffering or a critical health situation requiring rapid management. Urologists, in their daily practice face a large number of situation that require emergency management characterized by pain and a risk of serious functional sequelae or death of the patient [1]. In Africa urological emergencies are dominated by the urinary retention [2, 3] while in Europe renal colic prevails.

$[1,4,5]$. The aim of our work was to assess the epidemiological, diagnostic and therapeutic aspects of urological emergency in a university hospital.

\section{Patients and Method}

We conducted a single-center descriptive study of over the period January 2015 to December 2017. We collected data from the medical records of patients referred to the emergency units of the urology-andrology department of our center. The variables studied were: the age and sex of the patients, the nature of the urological emergency and its emergency management. Data collection and analysis were done with Excel 2017 Software. We performed descriptive analysis. 


\section{Results}

Three hundred patients were identified, representing a hospital frequency of 8.3 cases per month. Mean age of the patients was $47.8 \pm 22.9$ years ( 2 years to 92 years). The sexratio was 10.5 . The predominant emergencies were hematuria (25.6\%) and urinary retention (21.6\%). (Table 1). The number of emergency hospitalization was $230(76.7 \%)$. We performed 143 emergency surgical procedures $(47.6 \%)$. The main procedure performed was exploratory scrototomy (41.9\%), debridement of the external genitalia with cystostomy $(23.8 \%)$ and a suprapubic catheter placement (11.9\%) (Table 2). Three patients died, two patients with scrotal cellulitis and the other death was reported in a patient with obstructive anuria. The overall mortality was $1 \%$. Haematuria was common in elderly (mean age $=64.5$ years) and male (sex ratio $=7.5$ ) patients. The etiology of haematuria was dominated by bladder tumors $(42 \%)$ and prostate tumors (39\%) (Figure 1). The emergency management consisted in placing a 3-way transurethral bladder catheter associated with bladder irrigation with physiological saline. Twelve patients had an iso-group iso-rhesus blood transfusion before severe anemia. Urinary retention was commonest among the elderly (mean age $=64.9$ years) and the males (sex ratio=12). Chronic incomplete retention of urine was more frequent $(83.1 \%)$ compared to the acute retention $(16.9 \%)$. The etiology of urinary retention was dominated by prostate tumors $(67.7 \%)$ and urethral stricture $(16.9 \%)$ (Figure 2 ). Management of urinary retention consisted of drainage by transurethral bladder catheterization $(67.7 \%)$ and suprapubic catheterization (32.3\%). Scrotal cellulitis accounted for $10 \%$ of urological emergencies and was the main infectious emergency (52.6\%). In this case, a suprapubic catheter associated with debridement and antibiotic therapy was systematically performed. The second infectious emergency was acute pyelonephritis $(19.3 \%)$ occurring mainly in young adults with an average age of 44.5 years. The symptomatology was dominated by pain in the lumbar fossa $(100 \%)$ and infectious syndrome $(63.6 \%)$. All patients diagnosed with acute pyelonephritis were hospitalized and treated with intravenous antibiotic therapy and subsequent oral antibiotherapy after 2-3 days of apyrexia. Torsion of the spermatic cord was noted in 53 patients $(17.6 \%)$ with a mean age of 22.9 years. Eighteen patients underwent orchiectomy due to a necrotic testicle. Penile fracture due to coitus misstep was the main traumatic emergency $(4.6 \%)$. Seventeen patients $(5.6 \%)$ presented a priapism, including five cases in a context of sickle cell disease (AS Hemoglobin).

Table 1. Distribution of patients according to urological emergency.

\begin{tabular}{lll}
\hline Emergency diagnosis & Number (n) & Frequency (\%) \\
\hline Haematuria & 77 & 25,6 \\
Urinary retention & 65 & 21,6 \\
Imcomplete urinary retention & 54 & 18 \\
Complete urinary retention & 11 & 3,6 \\
Urogenital infection & 57 & 19 \\
Scrotal cellulitis & 30 & 10 \\
Acute pyelonephritis & 11 & 3,6 \\
Acute orchiepididymitis & 7 & 2,3 \\
Acute Prostatitis & 5 & 1,6 \\
Fournier's gangrene & 4 & 1,3 \\
Spermatic cord torsion & 53 & 17,6 \\
Uro-genital trauma & 27 & 9 \\
Penile trauma & 14 & 4,6 \\
Scrotal trauma & 7 & 2 \\
Kidney trauma & 4 & 1,3 \\
Bladder trauma & 2 & 0,6 \\
Priapism & 17 & 5,6 \\
Nephretic colic & 3 & 1 \\
Obstructive anuria & 1 & 0,3 \\
Total & 300 & 100 \\
\hline
\end{tabular}

Table 2. Distribution of emergency procedures.

\begin{tabular}{lll}
\hline Surgical Treatment & Number (n=143) & Frequency (\%) \\
\hline Exploratory scrototomy & 60 & 41,9 \\
Debridement + diversion cystostomy & 34 & 23,8 \\
Cavernous sponge shunt & 16 & 11,2 \\
Cavernosponge anastomosis & 12 & 8,4 \\
Suprapubic tube & 17 & 11,9 \\
Nephrostomy & 4 & 2,8 \\
Total & 143 & 100 \\
\hline
\end{tabular}




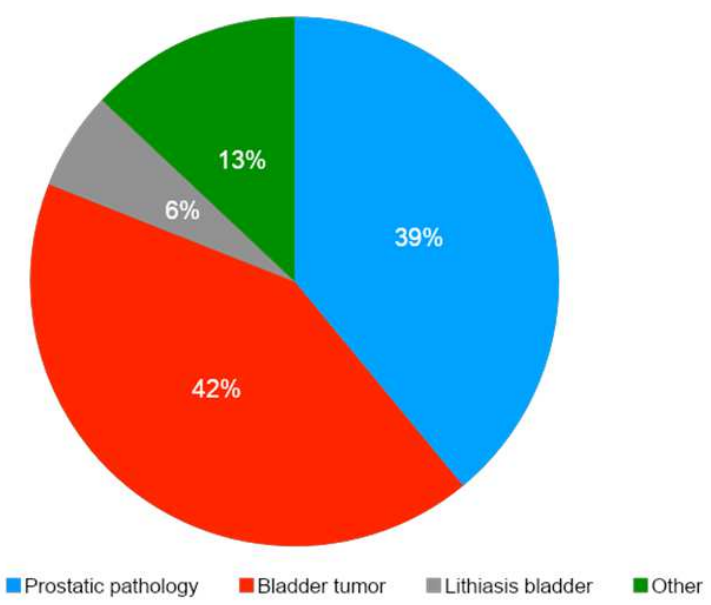

Figure 1. Distribution of different etiologies of haematuria.

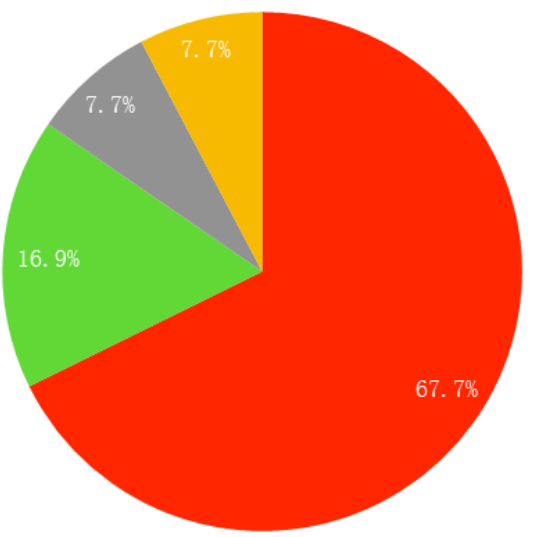

Prostate tumor "urethral stenosis "Lithiasis bladder "Other

Figure 2. Distribution of etiology of urinary retention.

\section{Discussion}

There is a clear regression of the number of referral to urological emergency unit in our center from 64.9 cases per month in the series of Fall [3] in 2008 to 8, 3 in our series. This drop could be explained by the increase in urology centers in Dakar and its suburbs but also by the growing number of urologists surgeons trained who are subsequently assigned peripheral area. So in two Senegalese series made in rural areas, Diabate et al. in Louga and Diamé et al. in Ourossogui $[6,7]$ reported a respective frequency of 11.7 and 85.1 cases per month. Besides the frequency, there is a variation of the average age in our center which passed in 11 years from 58.8 years [3] to 47.8 years. This decrease in average age is probably due to the increase in haematuria associated with bladder tumors. Indeed, the latter most often interest young adults [8], there is also an increase in the frequency of urogenital infections which are affections of young adults. Urological emergency most often interest men as evidenced by the series by Diabaté et al. and Diallo et al. $[6,2]$. This male predominance is explained by the frequency of andrological emergency (orchid-epididymitis, priapisms, prostatitis, spermatic cord torsion) but also by the fact that the main emergency in our series (urinary retention and haematuria) were related to prostate tumors. Haematuria was the main emergency in our series and supplanted the urinary retention which was the first emergency in the series of B Fall et al. [3]. This increased prevalence of hematuria is closely correlated with the increased number of bladder tumors [8]. However, urinary retention remains a very common emergency. In most African series, it remains the first urological emergency and is mainly related to prostate tumors $[2,3,6,9]$. Indeed in our context due to the ignorance of the disease and the limited health coverage in the community, these prostate tumors are most often diagnosed at an advanced stage and in particular the urinary retention $[9,10]$. Urogenital infections constituted an important part of urological emergency in our series with scrotal cellulitis being the main threat. While in the European series the prevalence of scrotal cellulitis is almost zero $[1,4,5]$. Scrotal cellulitis was the primary cause of death in our series. Indeed scrotal cellulitis is a medical-surgical emergency that can cause severe sepsis. Reducing the prevalence of scrotal cellulitis would require prevention and early management of urethral stenosis. Our emergency hospitalization rate was high compared to those reported in African series [3,6]. This is due to the high prevalence of haematuria, incomplete chronic urinary retention and scrotal cellulitis in our series. Mortality was low in our series, however Diabaté et al. [6] did not report any death in their series.

\section{Conclusion}

Urogenital tumors (bladder, prostate) are the main causes of urological emergency dominated by haematuria and urinary retention. Primary prevention of these emergency is primarily based on early and adequate management of genitourinary tumors.

\section{Conflict of Interest Statement}

All the autors do not have any possible conflicts of interest.

\section{References}

[1] Mondet F, Chartier-kastler E, Yonneau L, Bohin D, Barroub, Richard F. Epidémiologie des urgences urologiques en Centre Hospitalier Universitaire. Prog Urol 2002; 12: 437-442.

[2] Diallo AB, Bah I, Diallo TMO, Bah OR, Amougou B, Bah MD et al. Le profil des urgences urologiques au CHU de Conakry, Guinée. Prog Urol 2010; 20: 214-218.

[3] Fall B, Diao B, Fall P. A, Diallo Y. Sow Y, Ondongo AAM et al. Les urgences urologiques en milieu hospitalier universitaire à Dakar: aspects épidémiologiques, cliniques et thérapeutiques. Prog Urol 2008; 18 (10): 650-653. 
[4] Parra ML, Lopez Pacios JC, Pineiro FMC, Sanchez MJM, Menedez CMJ, Astorgano de la Puente $\mathrm{C}$ et al. Urologic disease emergency: clinico-epidemiolgic analysis at a district hospital. Arch Esp Urol 2001; 54: 411-415.

[5] Danuser H, Ackerman DK, Studer EU. Urological emergencies. Schweiz Med Wochenschr 1993; 123: 749-55.

[6] Diabate I, Ondo CZ, Sow I, Ba A, Mboup C. Les urgences urologiques au centre hospitalier de louga, Sénégal: aspects épidémiologiques et évaluation de la prise en charge. AFJU 2015; 21 (3): 181-186.

[7] Diamé ID, Diallo I, Beye M, Ndour NS, Ndiaye M, Hafing T. et al. Les aspects cliniques et thérapeutiques des urgences urologiques dans une zone rurale périphérique du Sénégal. Uro'Andro 2019; 2 (1): 34-37.

[8] Diao B, Amath T, Fall B, Fall P. A, Diémé M. J, Steevy N et al. Les cancers de la vessie au Sénégal: particularités épidémiologiques, cliniques et histologiques. Prog Urol 2008; 18 (7): 445-448.

[9] Ikuerowo SO, Ogunade AA, Ogunlowo TO, Uzodimma CC, Esho JO. The burden of prolonged indwelling catheter after acute urinary retention in Ikeja-Lagos, Nigeria. BMJ 2007; 7: 16.

[10] Thomas K, Oades G, Taylor-Hay C, Kirby RS. Acute urinary retention: what is the impact's on patient quality of life? BJU Int 2005; 95: 72-76. 